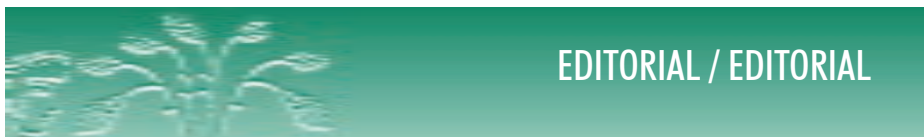

DOI: 10.12957/demetra.2017.27756

\title{
Trabalho editorial constante, mesmo na adversidade!! A UERJ, mais do que nunca, está viva!! E assim seguirá!!
}

Constant publishing work, even in hardship!! UERJ is more alive than ever!! And so shall it remain!!

Tantos pontos de exclamação não vêm ao texto à toa.

Como é do conhecimento de todos, a Universidade do Estado do Rio de Janeiro - a muito querida UERJ, instituição pública que acolhe nosso periódico - encontra-se atravessando uma das mais fortes turbulências desde sua criação.

Buscando divulgar o cenário em que estamos inseridos e informando sobre os acontecimentos mais recentes, transcrevemos, neste editorial, a última nota produzida no âmbito do Fórum de Diretores de Unidades Acadêmicas da UERJ, em 10 de fevereiro de 2017.

Nesse contexto, enfatizamos nossa disposição de prosseguir com os trabalhos da DEMETRA, mesmo em face de tamanhas dificuldades. Tal conduta assenta-se no sólido e constante apoio que recebemos da UERJ, do corpo editorial e da equipe técnica do periódico, sempre garantindo sua produção e publicação de modo muito respeitoso para com todos os autores, avaliadores e leitores que reconhecem e confiam na excelência acadêmica dessa grande Universidade.

Segue firme o nosso compromisso com a ciência e com a educação, como sempre!!

A UERJ está viva!!

E assim permanecerá!!

Shirley Donizete Prado e Fabiana Bom Kraemer

Editoras 


\section{Nota do Fórum de Diretores da UERJ}

A Reitoria da Universidade do Estado do Rio de Janeiro, após nova reunião com o Fórum de Diretores das Unidades Acadêmicas, com os Sub-Reitores e os Diretores dos Centros Setoriais, realizada em 10 de fevereiro de 2017, tendo em vista a sucessão de um conjunto de reuniões, nos últimos dias, com o novo secretário de Ciência, Tecnologia, Inovação, uma reunião com o Excelentíssimo Senhor Governador e uma outra com o Ministério Público, abrindo novos canais de negociação, visando dotar a Universidade de condições básicas de funcionamento, definiu que ainda não é possível que a UERJ inicie as aulas, no próximo dia 13 de fevereiro, como anteriormente almejado.

A Reitoria, juntamente com o Fórum de Diretores, reconhece a relevância do novo cenário de negociações que está em curso, pavimentando a construção de novos caminhos, visando à retomada integral das atividades acadêmicas na UERJ, em particular, o início das aulas do período letivo de 2016.2.

Nesse sentido, o Fórum de Diretores decidiu se manter reunido em caráter permanente, para acompanhar a concretização das negociações sinalizadas pelo Governo do Estado do Rio de Janeiro para a superação da grave crise que atinge a UERJ.

O Fórum de Diretores igualmente decidiu que o início das aulas se dará, em dois dias úteis, logo após o (re)estabelecimento das condições básicas para o funcionamento da Universidade, já devidamente apresentadas pela Reitoria, tanto à SECTI, quanto ao Governador do Estado e ao Ministério Público.

São elas, a apresentação de:

- calendário de repasses de verbas para a manutenção em geral, com previsão de cota financeira mensal;

- um plano de regularização dos pagamentos às empresas terceirizadas (manutenção, infraestrutura, limpeza, segurança, lixo e Restaurante Universitário);

- calendário de pagamento de salários, incluindo o décimo terceiro e de bolsas estudantis e demais modalidades. 
O Fórum de Diretores expressa sua expectativa positiva diante dos novos patamares de interlocução com o Governo do Estado e a demonstração efetiva da priorização da educação, da ciência, da tecnologia e da inovação em nosso Estado. Desse modo, o Fórum voltará a se reunir, presencialmente, no dia 16 de fevereiro, para avaliar os desdobramentos das negociações ora em curso.

A Comunidade Acadêmica, de um modo geral, vem expressando, com vigor, o desejo de retorno às aulas. Reafirmamos que o senso de responsabilidade continua a nortear as decisões até aqui tomadas pelos signatários, tendo em vista o compromisso do cumprimento integral da missão desta Universidade perante a comunidade universitária e a população do Estado do Rio de Janeiro.

Maria Georgina Muniz Washington - Reitora em exercício Tania Maria de Castro Carvalho Netto - Sub-Reitora de Graduação Elaine Ferreira Tôrres - Sub-Reitora de Extensão e Cultura Guilherme Teixeira Portugal-FAF

Fernando Padovani - FAF

Dirce Eleonora Nigro Solis - IFCH

Edna Maria dos Santos - IFCH

Renato dos Santos Veloso - FSS

Maria Claudia Pereira Coelho - ICS

Ronaldo Oliveira de Castro - ICS

Alexis Toribio Dantas - FCE

João Feres Júnior - IESP

Lincoln Tavares Silva - CEH

Rosana Glat-EDU

Eloiza da Silva Gomes de Oliveira - IFHT

Alexandre Sá Barreto da Paixão - IART

Ana Maria de Almeida Santiago - FFP

Luciano Ximenes Aragão - FEBF

Maria Tereza Cavalcanti de Oliveira - FEBF

João Pedro Dias Vieira - FCS

Márcia Regina de Faria da Silva - ILE

Maria Fátima de Souza Silva - CAp

Mariana da Costa Valim - CAp

Ana Maria Lopez Calvo de Feijoo - PSI

Flávio Chame - IEFD

Mário Sergio Alves Carneiro - CBI

Renata Rocha Jorge - ODO

Jorge José de Carvalho - IBRAG

Norma Albarello - IBRAG 
Eloá Carneiro Carvalho - ENF

Roberta Fontanive Miyahira - NUT

Rossano Cabral Lima - IMS

Edmar José Alves dos Santos - HUPE

Luis Antonio Campinho Pereira da Mota - CTC

José Roberto Pinheiro Mahon - FIS

Jacques Fernandes Dias - FAT

Zoy Anastassakis - ESDI

Marcos André Franco Martins - ESDI

Jorge Duarte Pires Valerio - FEN

Hindenburgo Francisco Pires - IGEOG

Rafael Angelo Fortunato - IGEOG

Alessandro Mendonça Filippo - FAOC

Lélia Maria de Araújo Kalil Thiago - FGEL

Geraldo Magela da Silva - IME

Marco Antonio da Costa - QUI

Ricardo Carvalho de Barros - IPRJ

Luis Cristóvão de Moraes Sobrinho Porto - PPC

Francisco José de Oliveira - PPC 